\title{
Can 8 Weeks of Training in Female Swimmers Affect Active Drag?
}

\author{
Daniel A. Marinho ${ }^{1,2}$, Nuno Garrido ${ }^{2,3}$, Tiago M. Barbosa ${ }^{2,4}$, Victor M. Reis ${ }^{2,3}$, António J. Silva ${ }^{2,3}$, \\ Aldo M. Costa ${ }^{1,2}$ and Mário C. Marques ${ }^{1,2, *}$ \\ ${ }^{I}$ University of Beira Interior, Sport Sciences Department (UBI, Covilhã, Portugal) \\ ${ }^{2}$ Research Centre in Sports, Health and Human Development (CIDESD, Vila Real, Portugal) \\ ${ }^{3}$ University of Trás-os-Montes and Alto Douro. Sport, Health and Exercise Department (UTAD, Vila Real, Portugal) \\ ${ }^{4}$ Polytechnic Institute of Bragança. Sport Department (IPB, Bragança, Portugal)
}

\begin{abstract}
Hydrodynamic drag is the force that a swimmer has to overcome in order to maintain his movement through water and is influenced by velocity, shape, size and the frontal surface area Thus, the aim of this study was to assess the effects of 8 weeks of training on active drag in young female swimmers. 8 female age group swimmers belonging to the same swimming club participated in this study. Active drag measurements were conducted in two different trials: at the beginning of the season and after 8 weeks of training. The velocity perturbation method was used to determine active drag in front crawl swimming. After 8 weeks of training, mean active drag decreased, although no significant differences were found between the two trials. No significant differences were observed in swimming velocity between the two trials. It seems that 8 weeks of swimming training were not enough to allow significant improvements on swimming technique. One can recommend that specific training sets concerning technique correction and improvement in young swimmers should be a main aim during training planning.
\end{abstract}

Keywords: Young swimmers, technique, drag, training effects.

\section{INTRODUCTION}

Hydrodynamic drag is the force that a swimmer has to overcome in order to maintain his movement through water and is influenced by velocity, shape, size and the frontal surface area [1]. The velocity perturbation method [2] was one of the methods developed to assess the drag of a person who is actively swimming. Further, active drag is dependent on swimming technique. Swimming with lower drag at any given velocity reduces the energy cost of swimming, and the movements do not contribute to excessive or unnecessary drag. Thus, the aim of this study was to assess the effects of 8 weeks of training on active drag in young female swimmers.

\section{METHODS}

8 females age group swimmers belonging to the same swimming club participated in this study $(11.63 \pm 0.52$ years old, $1.52 \pm 0.08 \mathrm{~m}$ and $40.50 \pm 8.98 \mathrm{~kg}$ ). All participants have been trained by the same coach and for the same club for the previous two years.

Active drag measurements were conducted in two different trials: at the beginning of the season and after 8 weeks of training (48 training units, $3.50 \pm 0.23 \mathrm{~km}$ per training unit). The velocity perturbation method [2] was used to determine

*Address correspondence to this author at the Department of Sport Sciences, University of Beira Interior - Portugal, Rua Marquês D’Ávila e Bolama, 6200-001 Covilhã, Portugal; Tel: +(351) 275329153; Fax: +(351) 275329157; E-mail: mariomarques@ mariomarques.com active drag in front crawl swimming. Both trials were conducted in a $25 \mathrm{~m}$ swimming pool and in-water starts were used.

\section{RESULTS}

After 8 weeks of training, mean active drag (drag force and drag coefficient) decreased, although no significant differences were found between the two trials $(29.18 \pm 15.24 \mathrm{~N}$ vs. $27.50 \pm 10.36 \mathrm{~N} ; 0.35 \pm 0.23$ vs. $0.30 \pm 0.09 ; \mathrm{p}>0.05$ ). No significant differences were observed in swimming velocity between the two trials $(1.23 \pm 0.13 \mathrm{~N}$ vs. $1.25 \pm 0.15 \mathrm{~N}$; $\mathrm{p}>0.05)$.

\section{DISCUSSION}

Drag force values of the current study were very similar to values found in other experiments conducted with children $[1,3]$. These values were quite lower than the values presented by adults, as expected [4]. Regarding drag coefficient, some controversy still remains. Kjendlie and Stallman [1] found drag coefficient values higher than the values found in the current study $(0.66 \pm 0.14)$ using a similar sample. However, Kolmogorov and Duplisheva [2] found similar values for this variable (drag coefficient: $0.28 \pm 0.09$ ). Thus, additional research is required regarding this issue.

It seems that 8 weeks of swimming training were not enough to allow significant improvements on swimming technique. One can recommend that specific training sets concerning technique correction and improvement in young swimmers should be a main aim during training planning. 


\section{REFERENCES}

[1] Kjendlie PL, Stallman. Drag characteristics of competitive swimming children and adults. J Appl Biomech 2008; 24: 35-42.

[2] Kolmogorov SV, Duplisheva A. Active drag, useful mechanical power output and hydrodynamic force coefficient in different swimming strokes at maximal velocity. J Biomech 2004; 25: 311-8.
[3] Toussaint HM, de Looze M, van Rossem B, Leijdekkers M, Dignum $\mathrm{H}$. The effect of growth on drag in young swimmers. Int $\mathbf{J}$ Sports Biomech 1990; 6: 18-28.

[4] Toussaint HM, Roos PE, Kolmogorov S. The determination of drag in front crawl swimming. J Biomech 2004; 37: 1655-63.

Received: July 05, 2009

Revised: October 10, 2009

Accepted: November 01, 2009

(c) Marinho et al.; Licensee Bentham Open.

This is an open access article licensed under the terms of the Creative Commons Attribution Non-Commercial License.

(http://creativecommons.org/licenses/by-nc/3.0/) which permits unrestricted, non-commercial use, distribution and reproduction in any medium, provided the work is properly cited. 